\title{
Natural Selection of Gender of the Baby at Conception: Proposing a Scientific Hypothesis
}

\author{
Inderjit Kaur Barthakur, ${ }^{1,}$, , Geeta Shroff ${ }^{2}$ \\ ${ }^{1}$ Retired Government Officer, New Delhi, India \\ ${ }^{2}$ Founder and Director of Nutech Mediworld, New Delhi, India \\ ${ }^{3}$ Vasant Kunj, New Delhi, India \\ Email address: \\ jkbarthakur@bol.net.in (I. K. Barthakur)
}

\section{To cite this article:}

Inderjit Kaur Barthakur, Geeta Shroff. Natural Selection of Gender of the Baby at Conception: Proposing a Scientific Hypothesis. Science Journal of Public Health. Vol. 3, No. 5, 2015, pp. 664-668. doi: 10.11648/j.sjph.20150305.21

\begin{abstract}
Genes and chromosomes interplay to produce unique human beings. Each cell contains a pair of sex chromosome. The sperms carry either ' $\mathrm{X}$ ' or ' $\mathrm{Y}$ ' chromosome, thus, they determine the sex of the offspring. Every couple happily accepts their first child, whether a girl or boy. Authors have developed a scientific hypothesis on the basis of which the couple can naturally choose the gender of their second baby at the time of conception. According to theory, ' $Y$ ' sperms are faster than ' $X$ ' sperms but they have a shorter life span. The emplacement of ovum occurs after the rise in temperature due to which coitus after ovulation results in a male zygote and vice versa. The authors have also discussed the relation of ovulation and basal body temperature. This hypothesis can result in bringing the population under control and remove many social ills such as female feticide and infanticide from the society.
\end{abstract}

Keywords: Chromosomes, Sperm, Ovum, Coitus, Ovulation, Basal Body Temperature

\section{Introduction}

Chromosomes and genes play an essential role in the hereditary process. Each chromosome carries genes or deoxyribonucleic acid (DNA) segments that contain the codes or genetic instructions producing particular traits and dispositions. A mature sperm and ovum contains 23 chromosomes (haploid) each, i.e., half of the set of 46 present in each parent's cells. When the sperm penetrates the ovum, fertilization occurs which combines the chromosomes via a complex mechanism. This ensures that the fetus has some genes from both the parents; the new life is influenced by the combined genes of the sperm and ovum contributing in fertilization. These genes guide the protein and enzyme reactions for every subsequent cell in the developing person and across the life course. Sex chromosomes, i.e., ' $\mathrm{X}$ ' and ' $Y$ ', determine the sex of the person such that a female comprises of ' $\mathrm{XX}$ ' chromosomes and a male carries ' $\mathrm{XY}$ ' chromosomes. As a sperm carry an ' $\mathrm{X}$ ' chromosome or a ' $\mathrm{Y}$ ' chromosome, it ensures the determination of the sex of a baby [1-3].

In 2014, China was observed as the most populous country with 1,364 million of population followed by India with
1,296 million [4]. The couples of such countries should follow the rule of bearing a single child or two, depending upon their income. The first child of a couple is precious, whether, a boy or a girl. The present study focuses in developing a scientific hypothesis to naturally determine the gender of the baby at the time of conception. The authors focus on the hypothesis that can assist the couples to bear their second child by gender determination.

\section{Hypothesis}

Table 1. Characteristics of $X$ chromosome and $Y$ chromosome carrying sperm

\begin{tabular}{lll}
\hline Characteristics & $\begin{array}{l}\text { X chromosome } \\
\text { carrying sperms }\end{array}$ & $\begin{array}{l}\text { Y chromosome } \\
\text { carrying sperms }\end{array}$ \\
\hline Motility & Slower & Faster \\
Fertilizing capacity & High/Long & Low/Short \\
Rate of facing hazards & Low & High \\
Waiting capacity & High & Low \\
\hline
\end{tabular}

On the basis of the differential properties and activities of ' $\mathrm{X}$ ' and ' $\mathrm{Y}$ ' chromosome carrying sperms, the authors have developed three hypothesis which assists in the determination of the sex of the baby at the conception. This 
influences the mating of the respective sperms with the ovum resulting in choice of gender of the baby at the time of conception. Table 1 explains the characteristics of ' $\mathrm{X}$ ' chromosome and ' $\mathrm{Y}$ ' chromosome carrying sperms.

\subsection{Hypothesis 1}

The first hypothesis states that the speed of motility of ' $\mathrm{Y}$ ' sperms is greater than that of the ' $\mathrm{X}$ ' sperms, i.e., the ' $\mathrm{Y}$ ' sperms swim faster than the ' $\mathrm{X}$ ' sperms. This gives ' $\mathrm{Y}$ ' sperms a greater chance of reaching the target due to their high speed. Sudden release of the ovum through stimuli enables the faster ' $Y$ ' sperms to raise the primary sex-ratio in favor of males. Therefore, when spermatozoa get deposited in the female genital tract at the time when the ovum is receptive/ awaiting, the chance of formation of a male zygote are relatively high, because the ' $\mathrm{Y}$ ' sperm, travelling with greater speed than that of the ' $\mathrm{X}$ ' sperm, reaches the ovum first.

\subsection{Hypothesis 2}

The second hypothesis is based on the difference in effective longevity of ' $\mathrm{X}$ ' and ' $\mathrm{Y}$ ' sperms. ' $\mathrm{X}$ ' sperms live longer than ' $Y$ ' sperms. When coitus takes place earlier than the release of the ovum, ' $Y$ ' sperms soon become a spent force/exhaust, and the ' $\mathrm{X}$ ' sperms who were following the ' $\mathrm{Y}$ ' sperms, fertilize the ovum and result into an ' $\mathrm{XX}$ ' or a female zygote.

\subsection{Hypothesis 3}
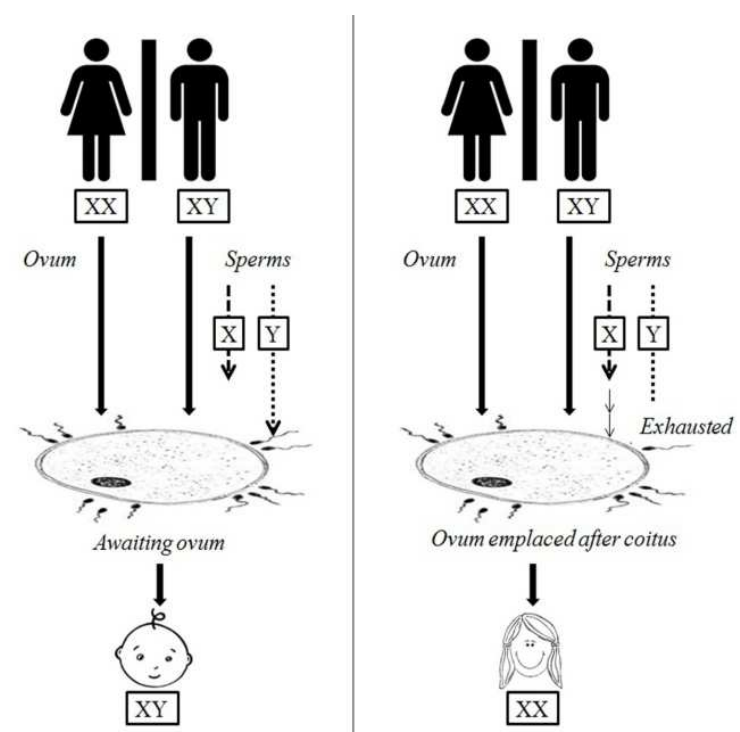

Figure 1. Choose the sex of your baby

The third hypothesis is based on the change in basal body temperature. It states that the ovum is emplaced on the day of the temperature rise. The rise in temperature could indicate changes in certain hormone levels for emplacement of an ovum. It is likely that the rise in temperature is required for the determination of emplacement.

If coitus takes place on the preceding evening or a day earlier to the temperature rise (which is approximately half way between the two menstrual periods), the ' $X$ ' sperms would wait and fertilize the ovum on its emplacement. It would result in a female zygote, unless an emotional stimulus in the woman, cause a sudden release of the ovum. Conversely, when a male child is desired, coitus must be avoided before the rise in temperature is noticed in the early hours of the day. Coitus should be planned after the rise in temperature, thus ensuring the emplacement of available ovum. Figure 1 represents the hypothesis involved in choosing the sex of baby at the time of conception.

\section{Discussion}

\subsection{Evolution of Sex Chromosomes}

The sex chromosomes are evolved from an ancient homologous pair of freely recombining autosomes and their existence was first proposed in 1920s. They were evolved due to lack of recombination in the heterogametic sex and erosion of ' $\mathrm{Y}$ ' chromosomes. There are various theories postulated to explain the degeneration of ' $\mathrm{Y}$ ' chromosomes such as effects of Muller's Ratchet, background selection model, weak selection Hill Robertson effect, etc. Due to the degeneration of the ' $\mathrm{Y}$ ' chromosome involving gene loss as well as chromatin state transitions, the ' $\mathrm{Y}$ ' chromosomes are smaller in size than ' $\mathrm{X}$ ' chromosomes [5-13].

\subsection{Difference in Size and Motility of Sex Chromosomes}

According to previous studies, the morphological measurements of ' $\mathrm{X}$ ' and ' $\mathrm{Y}$ ' spermatozoa differ. The ' $\mathrm{X}$ ' sperm are statistically longer and larger than ' $Y$ '. The mean area of ' $\mathrm{X}$ ' sperm heads is also found to be $6 \%$ larger than that of ' $Y$ ' sperms. The length of ' $X$ ' sperms head, neck and tail are significantly larger and longer than those of ' $\mathrm{Y}$ ' spermatozoa. The ' $X$ ' contains 3- 4\% more of DNA than ' $Y$ '. It is also reported that $X$ ' sperms bear $1 \%$ larger head radius 'than ' $Y$ ' sperms $[14,15]$. However, few studies reveal no consistent differences or distinguishing characteristics in dimensions or dimensional distributions was observed between ' $\mathrm{X}$ ' bearing and ' $\mathrm{Y}$ ' bearing spermatozoa [16-18].

The difference/increase in the size of ' $\mathrm{X}$ ' sperms than ' $\mathrm{Y}$ ' sperms might determine the speed and motility style of both of them. It is quite possible that the initial ejaculation of the sperms produces different speed in motility to ' $\mathrm{X}$ ' and ' $\mathrm{Y}$ ' sperms, due to differences in their tail length. The tail may provide a rhythmic balance and motility style separately peculiar to ' $\mathrm{X}$ ' sperms and ' $\mathrm{Y}$ ' sperms. Both the ' $\mathrm{X}$ ' and ' $\mathrm{Y}$ ' chromosomes differ in their swimming behavior due to the presence of a specific protein [19].

The condition of the female genital tract-cervical mucus, fluid of uterus and tubes also determine which of two types of spermatozoa would successfully reach and fertilize an egg at the time of ovulation to decide the sex of the baby [20].

\subsection{Previous Methods of Gender Selection}

The present theory is among those theories such as the one postulated by Ericsson, Shettles, etc., with some exception. 
The Ericsson's method, also known as the 'motility technique' was patented by Dr. Ronald Ericsson in the early 1980 's. The method used sticky albumin (a protein) solution on which the sperms were placed. As per theory, the ' $\mathrm{Y}$ ' sperms, being faster are supposed to swim down the sorting apparatus quicker than the ' $\mathrm{X}$ ' sperm, aiming to collect a sample enriched with desired spermatozoa. This method was used in case of artificial insemination. The act of patenting and obtaining opposite results made the technique conflicting and controversial. Dr. Landrum B Shettles and D. Rorvik were the first to publish their theory which stated that instead of the timing of intercourse with regard to ovulation, the artificially created chemical environment in the vaginal or genital tract of a female plays the major role in determining the sex of the baby. For a boy, enhanced alkalinity is required which can be achieved using baking soda douches. For a girl, female vagina and genital tract should have acidic environment which can be created by douching with diluted white vinegar. The major difference lies in the fact that this is a natural insemination method, whereas Shettles procedure is not. He has also recommended other methods/techniques which could help choosing the gender such as posture and frequency of intercourse. Dr. Shettles recommended vaginal penetration by the male from female's rear in the alkaline genital environment on the day of ovulation and missionary or face to face penetration in the acidic genital environment before ovulation for a boy and girl, respectively. Even clothing and drinks contribute to the choice of baby's gender. Loose fitting under clothes and 2-3 cups of coffee few minutes before coitus favor a boy, whereas tight fitting under clothes and taking no such drinks before coitus favors a girl [21-25].

Whelan Method, (published by Elizabeth Whelan in 1977) is virtually the opposite of the present hypothesis. The theory is based on the fact that biochemical changes occurring earlier in a woman's fertile phase favors a 'boy' sperm. It advises sexual intercourse about 4 to 6 days before ovulation for a boy and 2 to 3 days before ovulation for a girl [23].

\subsection{Our Hypothesis}

The present hypothesis also proposes the importance of the timing of sexual intercourse in choosing the sex of the baby. The woman's fertile phase is the most crucial element for achieving the conception of a baby of the desired sex. For boys, the method advocates to have sexual intercourse after ovulation and the rise in temperature (or the woman's egg release) and abstaining from sex for several days before this point in time. For girls, the method recommends coitus for the 2 to 4 days before ovulation.

According to the method, interplay of the natural differentiations of ' $\mathrm{X}$ ' and ' $\mathrm{Y}$ ' sperms could be used for the fertilization of the ovum with the sperm of the desired sex. This, however, requires the knowledge of ovulation time.

To detect ovulation, the identification of sexually active days (fertile window) of the menstrual cycle is of high clinical relevance [26]. Conception is possible from intercourse beginning about 5 days before ovulation extending through the day of ovulation [27, 28]. Traditional and widely used means of identifying the day of ovulation and the fertile window include basal body temperature and calendar calculations. Newer means include serial ovarian ultrasound, monitoring of hormones in urine, and fertility charting of vaginal discharge. Calendar calculation is an inexpensive method which is estimated on the basis of the previous/average cycle length. It is not accurate always due to variability in cycles for majority of women.

The change in the temperature of the basal body also indicates the post ovulation time of a body. The studies suggest the emplacement of ovum/ovulation after the rise in the basal body temperature. The body temperature of a woman is lower during the first part of the cycle (follicular phase). As soon as the ovulation occurs, the temperature rises by 0.5 to 1 degree and remains elevated through the second part of the cycle (luteal phase) under the influence of two key hormones, estrogen in the follicular phase and progesterone in the luteal phase. Though, it is an inexpensive method, it does not prospectively identify the approach of ovulation. Urine Leutinizing Hormone (LH) kits, ovarian monitors, etc. are other methods used to detect ovulation period of a woman [29, 30].

This brings the third hypothesis based on change in body temperature in a controversy. According to the present theory, the ovum is emplaced after the rise in temperature instead of before or at the time of rise. In other words, if coitus takes place on the day earlier of temperature rise, it is suitable for fertilizing the ovum with an ' $\mathrm{X}$ ' chromosome sperm, resulting in a female zygote. If the coitus occurs on the day after the shift in basal body temperature, it would result in fertilization of the ovum with ' $\mathrm{Y}$ ' chromosome sperm followed by male baby. However, the exact ovulation date varies with an individual's own menstrual cycle, and can be identified by the actual dip in the temperature.

The precision in ovulation timings might serve the purpose of deciding the safe or unsafe period for general family planning purposes, i.e., for avoiding pregnancy. But for hypothesis, a greater precision is required in determining the time of placement of the ovum. In order to achieve precision for deciding the sex of the child, a difference between the 'release' and 'emplacement' of ovum is to be maintained; because, by regulating the timings of the release of spermatozoa with the emplacement of ovum, the parents can choose the sex of their child at conception. There are methods which can easily determine the sex of the fetus/baby during pregnancy. An inexpensive, feasible and easily accessible technology, i.e., Ultrasonography (USG) is the technique used mostly for the same to deliver the baby of choice. However, such sex selection techniques have led to malpractices such as female feticides in India and worldwide. The abnormal or imbalanced sex ratio led to banning of sex determination of fetus/baby during pregnancy [31-33]. Indian Government has taken several steps to remove the gender disparity for which the Pre-Conception and Pre-Natal Diagnostic Techniques (PNDT). Act has been brought into action [24]. It is a law which bans sex determination before 
and after conception. Violations of the act can lead to penalty in the form of jail and fine. Even after strenuous efforts, the law has proved ineffective as it is difficult to regulate all clinics that use ultrasound for sex determination as well as for a host of other purposes including detection of genetic abnormalities in the fetus $[33,34]$.

The PNDT Act is rendered ineffective because of the liberal Medical Termination of Pregnancy (MTP) act which allows abortion on several grounds including mental trauma and failure of contraceptives. To eradicate female feticide from the society, there is a need to implement stricter laws for the couples as well as the surgeons. To plug the loopholes, registration procedures should be made tougher; surprise checks using dummy patients or direct; etc. [33].

The authors suggest the couples willing to have two kids not to use this hypothesis in determination of gender of their first baby. This may lead to abnormal sex ratio as couples of several countries have son preferences over daughters. The hypothesis should be followed only if the first child is a girl and the couple desires to have a male child as their second child or vice versa.

It is the first scientific natural theory in the world that enables a couple to naturally select the desired sex of their second child at the time of conception without interfering in the natural process. Besides, many other advantages are also associated with the present invention which might prove to be a boon to the society. Improvement in the health of the concerned families could be observed by avoiding sex linked genetic disorders as well as by decreasing women's physical, mental and emotional trauma of abortions or delivering an unwanted sex of child. The population health of the country would also be affected as heavy amount of funds spent by government on population issues could be saved. It would also eradicate the socials ills based on sex considerations such as female feticide, female infanticide, gender disparity, etc. from the society. The invention/discovery might also be effective in controlling the population explosion of the country which would speed up the economic development of the country.

This discovery neither requires money expenditure, nor clinical intervention from a fertility clinic. It does not harm the mother, father or the newly conceived baby and result in a successful pregnancy. It reveals the natural process of sex selection without interfering with the male or female reproductive organs; however, it does not give full guarantee a baby of the sex you desire.

All it needs the tracking and recording of female's menstrual cycle on a fertility chart using her physical signs such as temperature, mucous and cervix changes to estimate the time of ovulation.

\section{Conclusion}

It is a simple, intervention free method that can be followed in privacy to get the desired gender of second baby at the time of conception. If a male child is desired, the ovum has to be awaiting or match the arrival of the speedier ' $\mathrm{Y}$ ' sperm to fertilize it. On the contrary, if a female child is desired, the coitus must take place hours before the actual emplacement of the ovum for fertilization.

It depends upon who awaits, the ovum or the ' $\mathrm{X}$ ' or the ' $\mathrm{Y}$ ' sperm. If ovum waits, it's a boy; and if the sperms wait, it is a girl. The authors suggest the use of present hypothesis to choose the sex of the second child, because the Indian couples have son preferences, the world will be exploded with males creating abnormal sex ratio. The hypothesis should be used in favor of humanity to make this planet a better place to live.

Though, many situations can be explained through the use of the above postulated hypotheses; however, these could best be left out till the hypotheses are tested fully for their validity and till a greater understanding is achieved through tests.

\section{Acknowledgements}

The authors acknowledge Knowledge Isotopes Pvt. Ltd. (http://www.knowledgeisotopes.com) for the writing support.

\section{References}

[1] M. P. Harrigan, and S. M. Baldwin, "Chapter 2: Conception, Pregnancy, and Childbirth. In: Dimensions of human behavior: The changing life course," Available from: http://www.sagepub.in/upm-data/36522_CLC_Chapter2.pdf; Accessed on 29 January, 2015.

[2] F. W. Luthardt, and E. Keitges, "Chromosomal Syndromes and Genetic Disease. Encyclopedia of Life Sciences," Available from: http: //web. udl.es/usuaris/e4650869/ docencia/segoncicle/genclin98/recursos_classe_(pdf)/revision sPDF/chromosyndromes.pdf; Accessed on 29 January, 2015.

[3] P. F. Terranova, "Chapter 39: Fertilization, Pregnancy, and Fetal Development," Available from: http://faculty.ksu.edu.sa/15218/Medical\%20Books/Medical\% 20Physiology\%202nd\%202003\%20Rhoades/Medical\%20Phy siology $\% 202$ nd\%202003\%20Rhoades/smch39.pdf; Accessed on 29 January, 2015.

[4] "Sheet World Population," Available from: http://www.prb.org/pdf14/2014-world-population-datasheet_eng.pdf; Accessed on 29 January, 2015.

[5] T. S. Painter, "Study in mammalian spermatogenesis II. The spermatogenesis of man," J Exp Zool, Vol. 37 pp. 291-321, 1923.

[6] B. Charlesworth, "The evoluation of sex chromosomes science," Science, Vol. 251, 1991.

[7] J. J. Bull, Evolution of sex determinig mechanisms, Benjamin/Cummings Publishing Co. Advanced Book Program, Menlo Park, 1983.

[8] A. J. Solari, Sex chromosomes and sex determination in vertebrates, CRC Press, Boca Rotan, 1994.

[9] B. Charlesworth, "Evolution of chromosomal sex determinationand dosage compensation," Curr Biol, Vol. 6, pp. 149-62, 1996. 
[10] H. J. Muller, "The Relation of Recombination to Mutational Advance," Mutat Res, Vol. 106, pp. 2-9, 1964.

[11] J. Felsenstein, "The evolutionary advantage of recombination," Genetics, Vol. 78, pp. 737-56, 1974.

[12] B. Charlesworth, Morgan M. T., and Charlesworth D., "The effect of deleterious mutations on neutral molecular variation," Genetics, Vol. 134, pp. 1289-303, 1993.

[13] G. A. T. MacVean, and Charlesworth B., "The effect of HillRobertson interference between weakly selected mutations on patterns of molecular evolution and variation," Genetics, Vol. 155, pp. 929-44, 2000.

[14] K. H. Cui, "Size differences between human X and Y spermatozoa and prefertilization diagnosis," Mol Hum Reprod, Vol. 3, pp. 61-7, 1997.

[15] A. T. Sumner, J. A. Robinson., and H. J. Evans, "Distingiishing between $\mathrm{X}, \mathrm{Y}$ and YY-bearing human spermatozoa by fluorescence and DNA content," Nat New Biol, Vol. 229, pp. 231-3, 1971.

[16] Z. Zavaczki , C. Celik-Ozenci, L. Ovari, A. Jakab , G. L. Sati, D. C. Ward, et al., "Dimensional assessment of X-bearing and Y-bearing haploid and disomic human sperm with the use of fluorescence in situ hybridization and objective morphometry," Fertil Steril, Vol. 85, pp. 121-7, 2006.

[17] J. F. Moruzzi, A. J. Wyrobek, B. H. Mayall, and B. L. Gledhill, "Quantification and classification of human sperm morphology by computer-assisted image analysis," Fertil Steril, Vol. 50, pp. 142-52, 1988.

[18] J. O. Carvalho, L. P. Silva, R. Sartori, and M. A. Dode, "Nanoscale differences in the shape and size of $\mathrm{X}$ and $\mathrm{Y}$ chromosome-bearing bovine sperm heads assessed by atomic force microscopy," PLoS One, Vol. 8, pp. e59387, 2013.

[19] S. Sarkar, D. J. Jolly, T. Friedmann, and O. W. Jones, "Swimming behavior of $\mathrm{X}$ and $\mathrm{Y}$ human sperm," Differentiation, Vol. 27, pp. 120-5, 1984.

[20] K. P. Skandhan, "Hypothesis: Who is responsible for sex of offspring?," Trends in medical research, Vol. 6, pp. 161-168, 2011.

[21] I. K. Barthakur, "Naturally choose the sex of your child at conception," 1976.

[22] R. M. David, and L. B. Shettles, Choose your baby's sex-the one selection method that works, Dodd Mead \& Company, New York, 1977.

[23] "gender Choosing your baby's," Available from: http://www.birth.com.au/how-conception-works/choosing-thesex-of-your-baby; Accessed on 29 January, 2015.

[24] D. M. Rorvik, and L. B. Shettles, Your Baby's Sex: Now You Can Choose, New York City: Bantam Books, ISBN 978-0553-14277-8, 1980.

[25] L. B. Shettles, and R. M. David, "How to choose the sex of your baby-The method best supproted by scientific evidence, Newly revised edition, DOUBLE DAY, New York, London, Toronto, Sydney, Auckland, 1989.

[26] A. Chandra, and E. H. Stephen, "Impaired fecundity in the United States: 1982-1995," Fam Plann Perspect, Vol. 30, pp. 34-42, 1998.

[27] A. J. Wilcox, C. R. Weinberg, and D. D. Baird, "Timing of sexual intercourse in relation to ovulation. Effects on the probability of conception, survival of the pregnancy, and sex of the baby," N Engl J Med, Vol. 333, pp. 1517-21, 1995.

[28] D. B. Dunson, D. D. Baird, Wilcox A. J., and C. R. Weinberg, "Day-specific probabilities of clinical pregnancy based on two studies with imperfect measures of ovulation," Hum Reprod, Vol. 14, pp. 1835-9, 1999.

[29] "Temperature Basal body," Available from: http://www.integrativemedicinesf.com/pdf/BasalBodyTemper atureDirections.pdf; Accessed on 2 February, 2015.

[30] J. B. Stanford, G. L. White, and H. Hatasaka," Timing intercourse to achieve pregnancy: current evidence," Obstet Gynecol, Vol. 100, pp. 1333-41, 2002.

[31] "Daughters Genocide of India's," Available from: http://www.dailymail.co.uk/news/article-393896/GenocideIndias-daughters.html; Accessed on 29 January, 2015.

[32] S. M. George, "Sex selection/determination in India: contemporary developments," Reprod Health Matters, Vol. 10, pp. 190-2, 2002.

[33] S. Garg, and A. Nath, "Female feticide in India: issues and concerns," J Postgrad Med, Vol. 54, pp. 276-9, 2008.

[34] S. M. George, "Millions of missing girls: from fetal sexing to high technology sex selection in India," Prenat Diagn, Vol. 26, pp. 604-9, 2006. 